\title{
TEATRO RENASCER: DA PEDAGOGIA À POÉTICA DA CENA
}

O artigo descreve o processo artístico e pedagógico do Teatro Renascer formado por um grupo de pessoas com mais de 60 anos. A prática dialoga com a teoria do teatro de reminiscências, onde histórias de vidas e fragmentos de memória constituem o material dramatúrgico a ser jogado em cena.

Palavras-chave: teatro de reminiscências, pedagogia, terceira idade.

\section{Abstract}

The article describes the Renascer theatre Group`s artistic and educational processes. Renascer is a Theatre group made up of elderly people. Their works dialogue with reminiscence theatre theories, where life histories and memories fragments become the dramatic material to be explored on stage.

Keywords: reminiscence theatre, pedagogy, old age. 


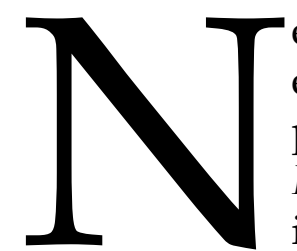
este artigo, analiso a experiência artística e pedagógica do Teatro Renascer formado, inicialmente, por mulheres com idades entre 60 a 80 anos, estabelecendo um diálogo entre a iniciativa e a área do Teatro em Comunidades, mais especificamente, do Teatro de Reminiscências. Este grupo foi criado por mim, no ano de 2005, como projeto deextensãouniversitária do Departamento do Ensino do Teatro da Universidade Federal do Estado do Rio de Janeiro - UNIRIO. ${ }^{2}$

A ação está inserida no contexto das diferentes práticas teatrais que atualmente integram o campo da Pedagogia do Teatro e que têm levado o fazer e fruir teatral a espaços diversificados, ampliando o seu acesso a diferentes segmentos da população (PUPO, 2008, p. 59). Apesar da iniciativa ter surgido de uma atividade de extensão, tornou-se logo um projeto de pesquisa com o propósito de investigar metodologias teatrais apropriadas ao contexto da terceira idade e conhecimentos sobre a área do envelhecimento.

A pesquisa surgiu associada a dois focos de interesse. Primeiro, à resposta positiva do grupo aos exercícios de yoga e segundo, às histórias de vida ou reminiscências compartilhadas, constantemente, pelos participantes. Estas histórias constituíram a base do material dramatúrgico a ser jogado teatralmente pelo grupo. Num primeiro momento, as histórias foram desencadeadas e selecionadas segundo a lógica e a sequência dos chakras ou centros de energia, estudadas pelo yoga.

A opção pelo yoga passou, também, pela preocupação com a saúde e o cuidado com o corpo do idoso. Era notável a

1 Mestre em Artes Cênicas, Professora do Departamento do Ensino do Teatro da Universidade Federal do Estado do Rio de Janeiro - UNIRIO. Autora do livro: Pedagogia do Jogo Teatral: uma poética do efêmero: o ensino do teatro na escola pública. São Paulo: Ed. Hucitec, 2010.

2 Além do grande incentivo do Professor Luciano Pires Maia, participaram da criação do Teatro Renascer, no ano de 2005, Inês Petereit e Fábio Fortes, ambos alunos do curso de Licenciatura em Teatro - UNIRIO. modificação dos humores no transcorrer das oficinas. As queixas iniciais em relação a dores e problemas de saúde, trazidas no início do dia, eram superadas pela alegria e vivacidade experimentadas durante o processo. ${ }^{3}$

Procurando associar procedimentos teatrais à noção dos centros de energia do corpo, trabalhamos, no início, sobre o primeiro chakra, conhecido como muladhara, situado na base da coluna, cujo órgão de ação são os pés. Ele representa o chakra da raiz, da ancestralidade e, por sua vez, está relacionado ao instinto de sobrevivência. Os pés são, também, aqueles que nos conduzem ao nosso destino. Assim como a maioria das raízes de uma árvore se contorce ao penetrar a terra, os pés trazem as marcas e o esforço de sua trajetória de vida. Queríamos, deste modo, revelar a beleza e a teatralidade contidas nos contornos e dobras dos pés dos próprios idosos, marcados pelo tempo e pela sua história de vida. Desejávamos que os idosos descobrissem a força de sua história construída através de seus próprios pés.

Outro motivo também encontrado para trabalhar os pés era de caráter preventivo e funcional. Pesquisas recentes na área da saúde revelam que as quedas representam a sexta causa na morte de idosos. Deste modo, a noção dos pés e o andar consciente tornaram-se um dos focos do trabalho. Nesta fase, utilizamos jogos teatrais que permitissem aos participantes descobrir a expressividade e a teatralidade dos pés, assim como caminhadas conscientes no espaço, lavapés, exploração de tapetes sensoriais.

As memórias dos idosos se revelaram para nós como um rico material tanto para o exercício da dramaturgia quanto para a construção da escritura cênica e passamos a utilizá-las como tal. A coleção de memórias para o aproveitamento cênico vai ao encontro das práticas e reflexões incluídas

3 A prática do yoga consiste na execução ativa de uma seqüência de exercícios corporais e respiratórios que atuam no sistema psicofísico do indivíduo gerando bem-estar e promovendo a saúde. 
no campo do teatro de reminiscências. Os facilitadores deste tipo de teatro assumem, dentre outras, a função de colecionadores de memórias, recolhendo histórias pessoais dos idosos e arquivando-as, realizando depois a sua transposição para a cena e a apresentação diante do público.

De acordo com Helen Nicholson, "o teatro de reminiscências tem sua raiz nos serviços de saúde e assistência social, onde a terapia de reminiscência era usada para encorajar o bem estar social e psicológico de pessoas idosas" (NICHOLSON, 2009, p. 268, trad. nossa). Utilizando como eixo metodológico a troca de histórias e fragmentos de vida, o teatro de reminiscências valoriza a afirmação de identidades e escolhas, a experiência dos idosos, conferindo aos participantes um sentimento de pertencimento social. Segundo Arigho:

O trabalho com reminiscências é essencialmente uma abordagem centrada na pessoa. O objetivo é compreender o ponto de vista dos indivíduos sobre suas próprias experiências e dar a eles a oportunidade de dividir suas histórias com uma larga audiência na forma de um produto educacional e artístico (ARIGHO In: NICHOLSON, 2009, p. 270, trad. nossa).

No Teatro de Reminiscência, como vertente do teatro em comunidades, podemos identificar dois tipos de dinâmica. Uma em que o teatro é criado com as comunidades e a outra em que o teatro é criado pelas comunidades. De acordo com Márcia Pompeo Nogueira, o teatro feito com a comunidade é construído por um grupo de profissionais "de fora" da comunidade, a partir de suas experiências e histórias de vida:

Aqui, o trabalho teatral parte da investigação de uma determinada comunidade para a criação de um espetáculo. Tanto a linguagem, o conteúdo - assuntos específicos que se quer questionar - ou a forma - manifestações populares típicas - são incorporados ao espetáculo. A idéia de vinculação a uma comunidade específica estaria ligada à amplificação da eficácia política do trabalho (NOGUEIRA, 2009, p, 177).

Neste primeiro caso, agentes externos lideram o processo de criação, podendo ou não incluir os integrantes da comunidade com a finalidade de discutir temas relevantes para determinado local. Em alguns casos, esses agentes pesquisam os temas durante workshops com os participantes, depois preparam a cena e retornam ao local com um espetáculo pronto.

Já o teatro feito pela comunidade esclarece Nogueira: "Inclui as próprias pessoas da comunidade no processo de criação teatral" (NOGUEIRA, 2009, p. 177). Durante este processo os temas, expressões estéticas e valores próprios das comunidades são incorporados à cena.

A "modalidade" do teatro de reminiscências, como é conhecida no Reino Unido, esteve, em sua origem, mais associada à dinâmica do teatro com comunidades. Atualmente, entretanto, já é possível apontar algumas experiências do teatro de reminiscências baseadas na dinâmica do pela comunidade, ou seja, que contam com a participação dos idosos como atores da cena. Aqui no Brasil, um dos exemplos disto é a experiência de Beatriz Pinto Venâncio com um grupo de não atores idosos na Universidade Federal Fluminense (UFF). ${ }^{4}$ Venâncio cria de forma sensível "arquivos de lembranças" com uma trupe de mulheres idosas, transformando-os, posteriormente, em material dramatúrgico e cênico, encenado pelos próprios idosos.

O Teatro Renascer se enquadra na dinâmica do pela comunidade. Acrescentase, entretanto, mais uma qualidade. A experiência é enriquecida porque inclui os jovens universitários em formação, funcionando também como um laboratório de ensino e pesquisa, onde métodos e procedimentos teatrais para esta faixa etária da população são estudados.

4 VENÂNCIO, Beatriz Pinto. Pequenos espetáculos da memória. São Paulo: Hucitec, 2008. 
Nossainvestigaçãopassa, também, pela exploração dos diferentes instrumentos e procedimentos práticos utilizados para o resgate das memórias, assim como para a construção da escritura cênica. Na primeira fase de nosso trabalho, privilegiamos os processos de evocação da memória, colocando a ênfase no corpo do idoso, sua capacidade de jogo e presença cênica. Desejávamos testar um caminho contrário ao tradicional do texto à cena. Evocamos as memórias a partir da exploração direta do corpo e do movimento no espaço, de maneira que a narrativa oral pudesse surgir deste processo, invertendo a hierarquia da palavra sobre o corpo e imprimindo, desde já, ao espaço a formalização de uma proposta cênica.

O processo de experimentação ocorreu no sentido de investigar um corpo-memória e a possibilidade de reconhecer que "o corpo, assim como a mente, participa integralmente do processo poético de reconstrução ou reinvenção de uma memória" (NICHOLSON, 2009, p. 271, trad. nossa). Mobilizar as lembranças do grupo a partir da conscientização dos plexos de energia do corpo estava associado, também, ao nosso interesse em investigar as possibilidades expressivas do corpo do idoso e a sua capacidade de produzir sentido poético à cena.

O processo criativo com o chakra muladhara ou raiz resultou na aulaencenação Raízes, apresentada no ano de 2006. O elemento cênico em jogo nesta aula-encenação era uma mala marrom, marcada pelo tempo, que trazia guardada as lembranças antigas das participantes. A mala é instalada em cena por uma senhora negra, de presença forte, trajando um terno branco à moda dos malandros cariocas, que percorre o palco em diagonal, do fundo em direção a boca de cena. Como uma espécie de via crucis, o corpo desta senhora atriz se contorce a cada passo ao peso de tantas lembranças. A mala é colocada sob um foco de luz branca. Sobre ela, a senhora, num gesto de despedida e pesar, deposita uma rosa vermelha, como quem cerra um jazigo e dentro dele a morte. Esta imagem era dotada de teatralidade e beleza especial e surgiu de jogos de fisicalização e exploração do espaço.

As aulas-encenações resultam das histórias e dos jogos teatrais realizados durante as oficinas. Procuramos, ao final de cada ano, à maneira de uma colagem, selecionar e costurar os jogos e achados cênicos obtidos no decorrer do processo, de maneira a construir uma cena dotada de sentido e teatralidade, sem a preocupação, no entanto, de estabelecer um enredo ou sequência linear. Como pedagogos e artistas, buscamos apurar o nosso olhar para reconhecer os possíveis traços de teatralidade advindos dos jogos e, a partir daí, construir uma estrutura cênica.

$\mathrm{Na}$ primeira aula-encenação, a mala era o portador de memórias. Cada senhora retirava de dentro dela a sua história. "Hoje tem marmelada. Tem sim senhor!!!" Entoava vibrante uma senhora cujo avô havia sido artista de circo e mascate. Da valise, ela sacava tecidos finos, frascos de perfumes que, num discurso cheio de humor, tentava vender à plateia. A personagem do mascate se mesclava à do palhaço e memórias de pequenos jingles antigos de propaganda eram entoados. A esta, seguiram-se outras lembranças: a da primeira bicicleta e do tombo festejado pelo coro debochado das colegas; lembranças da época em que o pai colocava os filhos, ainda pequenos, para dormir no alto das árvores para escapar do bando de Lampião; o jardim de violetas que semeava a esperança nos momentos de sofrimento. Esta memória foi protagonizada por uma senhora que, vez por outra, "com a voz purificada pela fraqueza" como diria Clarice Lispector sussurra, admirada, aos nossos ouvidos: -“Este espaço é sagrado, é um templo. Eu entro aqui e sinto que estou num templo" (LISPECTOR, 2009, p. 29). Apesar das limitações físicas, esta senhora faz de cada acontecimento teatral uma cena de total entrega. Outra senhora reconta sua chegada à cidade do Rio de Janeiro e a visita à Rádio Nacional. Agora, 
a mala, transformada em rádio, toca marchinhas de carnaval, momento em que a plateia é convidada a se unir a ela, cantando e dançando.

Neste tom de festejo, o público é envolvido na ação cênica, fazendo do teatro local de celebração da vida. Clarice Estés, numa espécie de manifesto à velhice e à sua capacidade criativa proclama: "Ser velha enquanto jovem, ser jovem enquanto velha. Quando uma pessoa vive de verdade, todos os outros também vivem" (ESTÉS, 2007, p. 117). O entusiasmo de aprender é a marca do grupo de idosas do Teatro Renascer. Os jovens alunos que participam do processo criativo e os que presenciaram as apresentações revelam-se surpresos ao observar o frescor, a alegria e a disponibilidade dos idosos.

Assim, o desafio do Teatro Renascer é o de poetizar a vida, dando expressão à dor e à alegria por meio do fazer artístico, reconhecendo que a experiência da beleza, a fruição estética da alma existem nesta dinâmica viva do teatro. Neste sentido, cabe destacar a assertiva de Nicholson:

Nas sociedades onde as pessoas velhas frequentemente se sentem abandonadas e insignificantes, convencer os velhos de que suas memórias são interessantes e de que suas vidas são importantes é sempre um processo difícil, mas crucial. Ampliar ou celebrar suas vidas por meio da performance, confere não apenas aos participantes um sentido de valor pessoal, mas afirma sua identidade cultural, como também, oferece um desafio político para o futuro, recolocando o passado no presente. Esta é uma forma de fazer teatro que reconhece a desorganização da vida cotidiana, aceita os erros cometidos e resiste às resoluções fechadas ou prontas para os problemas sociais. Fala, contudo, sobre os valores da sociedade contemporânea e assegura a promessa de um futuro mais equânime (NICHOLSON, 2009 , p. 274, trad.nossa).

À aula-encenação Raízes, sucedeuse a aula Magnífica dedicada ao chakra anahata, que tem sua correspondência física e energética na região do plexo do coração. Este centro rege as emoções e os afetos. O seu desenvolvimento desloca a consciência humana para noções de equanimidade e compaixão.

Durante as oficinas teatrais investimos no trabalho de exploração e conscientização desta área do corpo por meio de exercícios de yoga, dança butô e jogos teatrais. Nesta fase do trabalho, o foco estava voltado para a exploração de exercícios de escuta e prontidão com o objetivo de intensificar a capacidade de jogo entre os participantes. Desejávamos, também, que a comunicação fosse além dos clichês e dos códigos puramente sociais. Assim partimos para a experimentação de uma proposição familiar aos participantes do grupo, a exploração do ato de abraçar. Um dos idosos classificou o abraço como um ato de "intimidade social" para justificar este contato mais próximo e íntimo com o corpo do outro.

Como investigar com os idosos uma linguagem artística onde o corpo é criador de signos? Como explorar com o idoso, geração que viveu tantos tabus em torno do corpo, a intimidade e o contato com o seu próprio corpo e o corpo do outro? Como o corpo do idoso, dentro de suas possibilidades expressivas, pode ser potencializado, superando limites e conferindo sentido à cena? Estas são algumas questões que norteiam o nosso trabalho nas oficinas.

Decidimos transpor o ato de abraçar para o espaço dojogo teatral. Nas primeiras tentativas, o gesto do abraço chegou carregado de clichês, sendo desenhado de maneira descritiva e superficial. Passamos então a explorar o abraço como um ato de entrega entre um corpo e outro. $\mathrm{Na}$ segunda fase, usamos o abraço como gatilho para evocar lembranças. Como diferentes formas de abraçar podem gerar memórias diferentes?

A exploração sensório-corporal constitui a base pedagógica de nosso trabalho. Desejamos que as lembranças ou reminiscências trazidas pelos idosos sejam re-alojadas e re-significadas a partir da experiência sensório-corporal. 
O trabalho pedagógico com o Teatro Renascer se direciona para a pesquisa de um corpo-memória capaz de trazer à tona a expressão viva e pulsante de uma lembrança ou acontecimento.

Para a criação da aula-encenação Magnífica, realizada no ano de 2007, incorporamos o exercício do abraço à cena, encenando as lembranças que surgiram a partir desta experiência, criando um momento de extrema delicadeza. Nesta encenação, evocamos, também, os arquétipos das Marias, sagradas e profanas, num jogo lúdico que deram vez, por um lado, a Maria do Rosário, Maria dos Remédios, Maria da Glória, Maria da Conceição e por outro lado, a Maria Bonita, Maria do Cais, Maria fofoqueira, Maria sem vergonha e tantas outras Marias.

Diferentes referências culturais e religiosas vieram à tona como expressão da fé e da crença espiritual de cada membro. $\mathrm{O}$ confronto entre crenças diferentes gerou um desconforto inicial no grupo, superado, aos poucos, pela compreensão da diversidade e de sua riqueza para o trabalho artístico.

Assim, introduzimos na cena a dança a Oxum como resultado da pesquisa feita nas oficinas teatrais em torno das danças afrobrasileiras e populares. ${ }^{5}$ Dançando e tendo em mãos um espelhoimaginário, as "Nossas Senhoras Atrizes" se enfeitavam com colares, brincos e pulseiras. Em movimentos ondulantes, cada uma enfrentava o espaço dentro do círculo e, bailando, apresentava ao público "a rainha" em sua beleza e esplendor. $O$ figurino branco, elemento comum em diferentes festejos religiosos, deixava a imaginação transitar de forma livre entre as lembranças das festas das pastoras, das festas de coroação de Maria, dos rituais com mães de santo.

Surge como personagem desta aulaencenação a figura de Emilinha Borba, a "eterna rainha do rádio", a "favorita da marinha". Reconstruímos com elas algumas passagens e lembranças em

5 As oficinas de danças afro-brasileiras e populares foram oferecidas, no ano de 2006, pela artista e professora Aíla Machado, na época, aluna do curso de licenciatura em Teatro da UNIRIO. torno do mito, que se transformaram em cena ao som de Chiquita Bacana, ${ }^{6}$ um dos grandes sucessos da cantora.

Estímulos sensoriais também são oferecidos ao público, que entra no teatro percorrendo um tapete de pétalas de rosas. No tablado, ele é disposto em círculo, delimitando o espaço de jogo, numa relação de proximidade com a cena. Ajoelhada sob um foco de luz uma senhora entoa uma oração budista, aprendida no Centro em que freqüenta e, vez por outra, compartilhada por ela durante as oficinas.

Ao centro outro foco de luz, desta vez uma velha senhora idosa tem seus pés sendo lavados numa bacia por uma jovem estudante, resgatando a importância e o papel da anciã como guardiã da memória e da tradição. A cena dialoga com a teoria. Helen Nicholson aponta como aspecto importante do teatro de reminiscências a possibilidade "de honrar e salvaguardar a cultura, a sabedoria e a experiência dos mais velhos" (NICHOLSON, 2007, p. 270, trad.nossa).

Deixando este foco, o olhar do espectador é transportado para um outro quadro, onde, à semelhança da grande ceia, as idosas compartilham um jantar de pedras, dando corpo a um episódio doméstico da vida de uma delas: a senhora prepara um jantar de pedras e serve à família, obedecendo de forma irreverente ao conselho do marido, que ao negar o dinheiro para a compra dos alimentos necessários ao jantar, lhe ordena que cozinhe e coma pedras; assim, quando o marido retorna do trabalho, ela serve, cerimoniosamente, com as melhores louças o jantar de pedras a ele e aos filhos.

Segue a esta cena um ritual de oferendas em que cada uma delas presta uma homenagem a Nossa Senhora. A aulaencenação chega ao fim de forma apoteótica com uma procissão à imagem de Nossa Senhora ao som de Magnificat. ${ }^{7}$

Compartilhando histórias de vida por meio de um quadro múltiplo de

6 Chiquita Bacana, marchinha de autoria de João de Barro e Alberto Ribeiro.

7 Magnificat - Johann Sebastian Bach. 
referências culturais e signos teatrais, a aula-encenação, como procedimento pedagógico e artístico, permite que as memórias recontadas ultrapassem "as fronteiras do corpo, espaço e tempo do contador, recolocando-as nos corpos e mentes dos performers e das audiências" (NICHOLSON, 2009, p. 272, trad. nossa).

As aulas-encenações são o resultado do processo criativo desenvolvido com o grupo e, depois, apresentado ao público. $\mathrm{O}$ seu formato surge como resposta ao perfil e às necessidades específicas do grupo, às condições materiais de trabalho e ao curto período de tempo disponível para as oficinas.

Por outro lado, o formato das aulasencenações favorece a investigação de uma pedagogia do teatro que reduz a distância entre exercício, jogo e teatro, reconhecendo no cotidiano das oficinas e na cena a teatralidade sendo confeccionada a cada momento. Maria Lúcia de Souza Barros Pupo, tecendo relações entre o campo da Pedagogia do Teatro e os procedimentos adotados pela cena pós-dramática, observa que: "Aquilo que muitas vezes é vivido como simples exercício ou imprecisa experimentação traz em si o germe de modalidades estéticas qualificáveis como manifestações de um teatro pós-dramático" (PUPO, 2008, p. 227).

No artigo intitulado $O$ pós-dramático e a pedagogia teatral, Pupo discute as possibilidades de implementação, hoje em dia, de uma ação educativa em que "o exercício e a fruição da cena" estejam sintonizados com procedimentos teatrais que se situam além do drama, e onde "distanciados da mimese, os seus responsáveis encontram na experimentação formal o vetor principal de seus esforços" (PUPO, 2008 p. 226). Para que a área da Pedagogia do Teatro possa avançar em direção a uma estética pós-dramática, Pupo destaca a importância da formação do olhar formador:

Do ponto de vista da formação do formador, ao que tudo indica o mais relevante parece ser que esse último possa se colocar numa espécie de permanente "estado de alerta" em relação ao tema. Para que esse estado se configure, algumas condições precisam ser satisfeitas: possuir uma informação sedimentada acerca do assunto e desenvolver uma sensibilidade específica no que tange às provocações implícitas no teatro atual. Assim fazendo, ele estaria apto a captar a emergência do caráter pós-dramático dentro do exercício, do jogo e da cena que vêm à tona dentro do processo. A partir daí, estará em condições de explicitar esse caráter e de fazer avançar processos de aprendizagem envolvendo as perspectivas por ele suscitadas (PUPO, 2008, p. 232).

A prática artística e pedagógica do Teatro Renascer convida todos os seus participantes, idosos, jovens universitários, a professora que aqui se dedicou ao relato, e porque não dizer também as plateias, a desenvolver novas perspectivas não apenas em relação ao próprio teatro, uma vez que nos provoca a captar traços de teatralidade no evento incompleto de um jogo teatral, ou de uma aula-encenação como também, em relação ao curso da vida e à velhice, para onde todos nós caminhamos.

Um convite à construção de novas percepções estéticas e existenciais.

\section{Referências bibliográficas}

ESTÉS, Clarissa Pinkola. A ciranda das mulheres sábias: ser jovem enquanto velha, velha enquanto jovem. Rio de Janeiro: Rocco, 2007. FLORENTINO, Adilson; TELLES, Narciso (Orgs.). Cartografias do Ensino do Teatro. Uberlândia: EDUFU, 2009.

LISPECTOR, Clarice. Felicidade Clandestina. Rio de Janeiro: Rocco, 2009.

NICHOLSON, Helen. Re-locating memory: performance, reminiscence and communities of diaspora In: PRENTKI, Tim; PRESTON, Sheila. The Applied Theatre reader. London and New York: Routledge, 2009.

NOGUEIRA, Márcia Pompeo. Teatro e Comunidade. In: FLORENTINO, Adilson; TELLES, Narciso (Orgs.). Cartografias do Ensino do Teatro. Uberlândia: EDUFU, 2009. 
PUPO, Maria Lúcia de Barros. Dentro ou fora da escola? In: Urdimento Revista de Estudos em Artes Cênicas da Universidade do Estado de Santa Catarina. Florianópolis, v. 1, n.10, dez. 2008.

. O pós-dramático e a pedagogia teatral In: GUINSBURG, J.; FERNANDES, Silvia (Orgs.). O pós-dramático. São Paulo: Perspectiva, 2008.

VENÂNCIO, Beatriz Pinto. Pequenos espetáculos da memória. São Paulo: Hucitec, 2008. 